\title{
Membranes and the water cycle: challenges and opportunities
}

\author{
A. G. Fane
}

Received: 21 January 2011/Accepted: 18 April 2011/Published online: 9 June 2011

(C) The Author(s) 2011. This article is published with open access at Springerlink.com

\begin{abstract}
Membrane technology for the water cycle has been around for about 50 years and is taking an increasingly important role in the provision of safe water supply and treatment and reuse of wastewater. It is timely to examine the challenges and the future of the technology. The challenges are both technical and socio-political and they provide the drivers for new developments. This paper summarizes the status of membranes in the water industry and discusses the major challenges and possible responses that will determine the possible futures.
\end{abstract}

Keywords Membrane technology - Water - Wastewater · Climate change $\cdot$ Future

\section{Introduction}

Membrane technology for the water cycle has been around for about 50 years and is taking an increasingly important role in the provision of safe water supply and treatment and reuse of wastewater. It is timely to examine the challenges and the future of the technology. The challenges are both technical and socio-political and they provide the drivers for new developments. This paper summarizes the status of membranes in the water industry and discusses the major challenges and possible responses that will determine the possible futures.

Following the invention of the cellulosic RO membrane in the 1960 s, the next two decades saw membranes applied

\section{A. G. Fane ( $₫)$}

Singapore Membrane Technology Centre,

NTU, Singapore, Singapore

e-mail: agfane@ntu.edu.sg

A. G. Fane

UNESCO Centre for Membranes, UNSW, Kensington, Australia

e-mail: a.fane@unsw.edu.au to desalination in water scarce areas and other niche water applications. The 1980s started to see applications in water treatment and water reuse. However, since the early 1990s, membranes have seen a dramatic growth across the spectrum. The growth has been particularly strong in the past 10-15 years due to the drivers of tighter regulations, water scarcity, and significant advances in membrane process performance. Recent surveys show the trends. The market for membranes for municipal water treatment is growing at over $10 \%$ pa reaching USD 1.6 billion by 2011 (BCC Research 2007). Desalination by RO is growing at a possibly faster rate, from about USD 5 billion in 2010 to over 10 billion by 2015/6 (Pankratz 2010). Membrane plant sizes continue to grow and Table 1 lists some of the largest plant in various categories. The large electrodialysis plant (EDR), for brackish water with high organic fouling, serves as a reminder that this technology continues to have a role. There is also a healthy market for membranes at the small 'commodity' scale, including point of use membranes (RO, UF, etc.) for water supply in households and a growing interest in recycling of greywater and blackwater using membranes. Decentralized treatment has intrinsic benefits that can make this a growth area for membranes.

\section{Challenges}

The challenges facing membrane technology are both technical and socio-political.

Technical challenges

In the context of technical challenges, there are at least three major issues, product quality, productivity (in terms of fouling), and energy usage and greenhouse gas (GHG) emissions. 
Table 1 Recent large scale applications of membrane technology to water and wastewater

\begin{tabular}{llll}
\hline Application & Scale (ML/day) & Location & Comment \\
\hline EDR & 200 & Abrera, Spain & Started 2008 \\
BWRO & 129 & Wadi Ma'in, Jordan & Started 2006 \\
SWRO & 500 & Magtaa, Algeria & Starting 2011 \\
WTP (UF) & 388 & San Diego, USA & Started 2008 \\
Reuse & 375 & Sulaibiya, Kuwait & Started 2005 \\
MBR & 117 & Brightwater, USA & Started 2009 \\
\hline
\end{tabular}

\section{Technical challenge: product quality}

There are some specific issues such as trace organics removal from some raw waters or reclaimed water. In most cases, these challenges are overcome by membranes coupled with other unit operations such as sorption, advanced oxidation, etc. An important quality issue arises with small decentralized systems where membrane integrity needs to be assured.

\section{Technical challenge: productivity}

Fouling is an ongoing challenge. Even 'simple' raw water contains low ppm levels of natural organic matter (NOM), which is a complex foulant. At the other end of the scale, more complex feeds are prevalent in membrane bioreactors (MBRs), where various components (proteins, polysaccharides, colloids) have been identified as likely foulants. The desire to achieve the maximum throughput requires high fluxes which tend to accelerate fouling. Low fouling membranes are the 'holy grail', but feed pretreatment is likely to remain an essential and challenging aspect of membranes and water.

\section{Technical challenge: energy and $G H G$}

These issues are also central to the socio-political challenges to be discussed below.

Socio-political challenges

In terms of socio-political issues, there are two pressing challenges facing membrane technology and the water cycle, as discussed below.

\section{Socio-political challenge: climate change}

The need to respond to climate change is a major challenge for the water industry and membrane technology. This requires a fundamental assessment of energy usage and GHG emissions. Recent pronouncements call for a cut in
GHG emissions by about $30 \%$ by 2020 and by 2050 for a cut of 60 or even $90 \%$. These targets will involve all sectors of industry, including the water industry which is not itself a major GHG emitter. However, membrane technology tends to use primary power and has an 'image' of being energy intensive. To put this into context, let us compare energy used by membrane (RO) desalination with energy for the global 'separations' industry. The global separations industry in 2005 consumed about $58 \mathrm{Q} /$ year $\left(58 \times 10^{15}\right.$ BTU/year or $\sim 60 \times 10^{18} \mathrm{~J} /$ year $)$ which was about $15 \%$ of global energy use (Koros 2006). An approximate estimate of installed seawater RO in 2005 is $9 \times 10^{6} \mathrm{~m}^{3} /$ day, and at $3.5 \mathrm{kWh} / \mathrm{m}^{3}$ (best available technology) the energy used would have been $<0.1 \%$ of separations energy. Assuming a 15\% annual growth in SWRO and 'business as usual' (BAU) for SWRO but a $30 \%$ cut in emissions for the separations area by 2020, the SWRO would then be about $1 \%$ of separations energy. By 2050, assuming a $90 \%$ cut in other areas, a BAU policy for SWRO could exceed all other separations. In the short term, a 'BAU' SWRO has only a small impact but in the long-term BAU SWRO is not sustainable.

The need for energy reduction in membrane technology is only part of the climate change story. Another aspect is that the climate change trends are also leading to water scarcity, which opens up opportunities for membrane technology, particularly in the reclamation of used water. A recent assessment for Europe (Hochstrat et al. 2006) concluded that reused water could save between 1 and $1.5 \%$ of the total water abstracted in the region by 2025 and in some parts the percentage could be as high as $5-30 \%$. In Australia, studies have shown how water reclamation and recycling can compensate for the projected impacts of climate change in water supply (Anderson 2007). Although the fouling issues may be more challenging in membranebased reclamation, the much lower salinity means costs of production are $<50 \%$ of SWRO and energy use is about $30 \%$ (Cote et al. 2005). The climate change 'drivers' of water scarcity and reduced GHG per unit water favor a stronger push to reclamation and reuse.

The treatment of wastewater containing biodegradable organics also contributes to GHG release. Whilst the carbon inventory is relatively modest and essentially recyclable, its treatment in ways that emit lower net GHGs may be feasible. The potential benefits in terms of GHG production from conventional anaerobic compared to aerobic treatment have been shown by Cakir and Stenstrom (2005), although for low strength wastewaters $(<300 \mathrm{mg} / \mathrm{L}$ BOD) the aerobic processes may emit less net GHG. For higher strength wastewaters, anaerobic treatment is favored as the methane produced can generate power to run the process and can even become a negative $\mathrm{CO}_{2}$ emitter if it offsets the use of fossil fuels. Questions arise in terms of sludge 
retention time (SRT), the need for polishing, dissolved methane removal from the treated effluent and the effect of preconcentration to increase biogas yield. The potential role of membranes in such situations needs to be assessed, and the responses to climate change present both a challenge and an opportunity for membranes and water.

\section{Socio-political challenge: Millenium Development Goals (MDGs)}

The MDGs aim to improve the quality of life of many of the under privileged by, inter alia, reducing by half the number of people without access to safe drinking water and basic sanitation by 2015 . To meet the MDGs requires new installations everyday of about 250,000 for safe water and 350,000 for basic sanitation. In 2006 (United Nations 2006), it was noted that there is a risk that the MDGs for water and sanitation will not be met, particularly if 'BAU' is applied. Membranes are already playing an important role in the delivery of safe water in areas of both chronic and acute need. For example, an Australian organization, the Skyjuice Foundation (see website) has provided over 1,000 microfiltration units (based on Siemens-Memcor Technology) to NGOs for placement around the world. These units produce up to $10,000 \mathrm{~L} /$ day by gravity feed. The key to this challenge is appropriate technology that is low cost, reliable and simple to maintain. Solutions also favor decentralization. Membranes are not a panacea but will have an important role.

\section{Potential responses and opportunities}

In the light of the above challenges, let us look at trends and potential developments in the use of membrane technology in the water cycle. The applications range from desalting, water treatment, water reclamation to MBRs. The potential developments include novel membranes, processes, operating strategies and the way we assess the membrane applications.

\section{Desalination}

$\mathrm{RO}$ is now the predominant method of desalting and was a paradigm shift when introduced in the 1960s. The Spiral Wound Module (SWM) was an early development and has been evolving over the years. The steady improvements in the SWM and RO membranes demonstrate the power of incremental change. The 'Figure of Merit' (FOM), defined by Birkett and Truby (2007), illustrates that from 1978 to 2006 , improvements in permeability $(2.25 \times)$ and life $(2.3 \times)$, price per unit area $(1 / 12)$ and salt passage $(1 / 7)$ translate to a 'FOM' increase from 1 to 480 . The FOM continues to rise due to use of Mega modules (16-18 in.) and improved thin film composite (TFC) membranes (see below). Other benefits may come from better spacer design as an outcome of CFD analysis (Schwinge et al. 2004). There could also be a resurrection of hollow fiber RO (HFRO), which is currently sidelined. HFRO could bring intrinsic advantages if revisited, e.g. with greatly improved (membrane) pretreatment and modules with better fluid management.

The standard RO membrane is a TFC and its introduction in the late 1970s was a major advance in membrane preparation resulting in greatly improved permeability and retention. Recently, there have been new developments involving thin film nanocomposite (TFN) RO membranes (Jeong et al. 2007). These mixed matrix membranes incorporate nanoparticles, such as zeolites, in the thin polyamide separating film, which imparts greater hydrophilicity, as well as improving water permeability without loss of retention properties. There is also interest in a new generation of super permeability RO based on either carbon nanotubes (Holt et al. 2006) or biomimetics, including aquaporins (Kumar et al. 2007). Significant breakthroughs are required to achieve the promise of these concepts. In addition, modules with improved strategies for polarization control will be required before super permeability membranes can be exploited.

\section{Desalination: energy issues}

Significant reductions in energy demand for SWRO have been demonstrated recently in the Affordable Desalination Collaboration project (Truby 2008). Using state-of-the-art SWM $\mathrm{RO}$ with isobaric pressure exchangers, the energy has been reduced to as low as $1.58 \mathrm{kWh} / \mathrm{m}^{3}$, down from the more typical $3 \mathrm{kWh} / \mathrm{m}^{3}$. It is of interest to note that the minimum water cost occurs at a recovery of about $50 \%$ whereas the minimum energy, and thus minimum GHG impact, occurs at a recovery of about $40 \%$. In other words, GHG minimization comes at a capital cost penalty for SWRO: a paradigm shift may be needed to adopt GHG minimization as the new optimum. There could also be opportunities for further energy reduction if novel super permeability RO membranes under development are used optimally. For example, it may be possible to reduce energy using a 'close to osmotic pressure' strategy with a multistage process, inter-stage booster pumps and energy recovery devices. Energy savings of about $30 \%$ could be feasible.

Two 'old' membrane technologies are receiving renewed interest as they offer alternative low GHG options for desalination, provided waste heat (or solar) is available. Figure 1 depicts these technologies. Membrane distillation (MD) is a thermally driven membrane process which has the benefit of ambient pressure and the ability to operate at 
very high salinity (Chan et al. 2005) so that overall recoveries $>80 \%$ may be feasible, possibly involving MD crystallization (Macedonio et al. 2011). Energy recovery or multiple effect is required in MD processes to improve thermal efficiency. Whilst MD cannot compete with RO, on a straight energy $/ \mathrm{m}^{3}$ basis it can have a lower GHG footprint if waste heat is used. The other membrane process with a long gestation time is forward osmosis (FO) which is having a surge of interest (Cath et al. 2006) as a potentially lower energy approach closer to the 'minimum work' for desalination. FO relies on water transport due to osmotic pressure difference, generated by a 'draw solute' (DS). Regeneration of the DS solution is required to yield the water product, and this can also be done thermally. The FO membrane provides a challenge as commercial RO membranes are not efficient due to internal concentration polarization. There is considerable effort to produce improved FO membranes. For example, a novel TFC hollow fiber has been recently developed with interesting performance (Wang et al. 2010). Both MD and FO appear to be membrane processes with promise.

Engineering heuristics suggest that an optimal separation process removes the least abundant species first, so that desalination should involve removal of salt from water rather than vice versa. This is the rationale behind the work on ED, coupled with electrodeionization, by Siemens in a project with a target for $1.5 \mathrm{kWh} / \mathrm{m}^{3}$, sponsored by Singapore.

\section{Water treatment}

In water treatment, the contaminants are typically pathogens, colloids, NOM and in some cases trace organic compounds (natural and synthetic). Low pressure membranes are playing a major role in water treatment, where MF and UF, possibly combined with chemical coagulation, remove all but the low MWt organics and inorganics. For such membranes, there is a need to improve retention at the

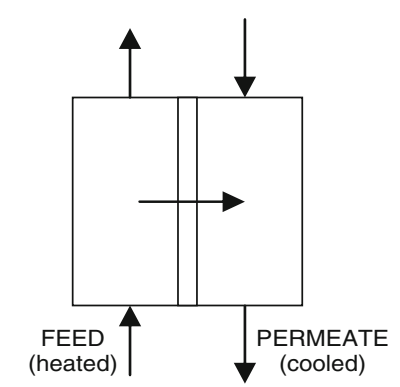

MEMBRANE DISTILLATION

(Vapour through hydrophobic microporous membrane temperature driving force)

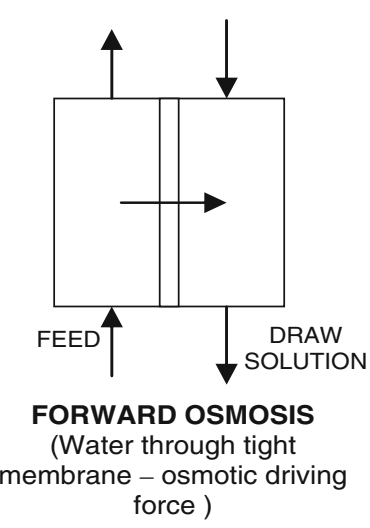

Fig. 1 Depiction of membrane distillation and forward osmosis same or higher water permeability, and this has been achieved by 'stretched pore' membranes (Morehouse et al. 2006), where the elongated pores achieve higher permeability along with lower molecular weight cutoff. A recent development is the commercial scale application of ceramic MF to water treatment. The $15 \mathrm{~m}^{2}$ modules from NGK have $0.1 \mu \mathrm{m}$ pore size and a very narrow pore size distribution, which alleviates fouling. The higher cost of ceramics is offset by much longer lifetime $(2-5 \times)$, greater chemical resistance as well as reportedly higher sustainable fluxes and recovery. Ceramic MF/UF is being pioneered by PWN Technologies (see PWN website). For the removal of low concentrations of organics in water treatment, the options include NF or low pressure 'hybrid' processes such as MF or UF with adsorbents or photocatalysis. The low pressure hybrid is potentially the lower energy option (Fane et al. 2005).

\section{Water treatment: energy issues}

In water treatment with low pressure membranes using upstream chemical coagulation or in low pressure membrane pretreatment in reclamation, the process is typically dead-end with batch filtration. The batch operation involves fixed flux with increasing transmembrane pressure (TMP) and a cycle time either fixed or set by the maximum TMP. For the latter scenario, the cycle time is inversely proportional to $(\mathrm{flux})^{2}$ and this means that for a given amount of product (filtrate) the number of backwashes increases with imposed flux. Each backwash consumes energy and consequently a high flux operation is more energy demanding, although it would require less membrane area. This implies a trade-off for economic optimum, although this may not be the environmental optimum. For example, we have compared the 'economic optimum' flux with the 'energy minimum' flux and shown for a specific case study that conventional economics suggest a flux of about $70-80 \mathrm{~L} / \mathrm{m}^{2} \mathrm{~h}$, whereas the minimum energy (minimum GHGs) requires a flux of only $10-20 \mathrm{~L} / \mathrm{m}^{2} \mathrm{~h}$ (Fane et al. 2005; Tangsubkul et al. 2006). This is another example where meeting a minimum GHG emission involves additional capital cost—inviting a paradigm shift in process selection criteria.

\section{Reclamation}

Membranes have become the enabling technology for safe and cost-effective wastewater reclamation. Typically, the reclamation process is a retrofit to an existing conventional activated sludge plant (CASP), followed by low pressure MF or UF, then RO and finally advanced oxidation. However, a preferred arrangement is the combination of a MBR and RO, since MBR effluent is easier to process 
(marginally lower residual organics). One of the challenges to RO in this application is biofouling and important agents in this process could be the 'viable but not culturable' (VNBC) bacteria that are dwarf bacteria capable of passing through some MF and UF membranes (Sadr Ghayeni et al. 1999).

Potential pretreatment strategies include inactivation by advanced oxidation, such as UV, or biomimicry with the addition of biofilm signaling agents that either disperse or interfere with quorum sensing (Barraud et al. 2009).

An alternative approach to reclamation is to incorporate a 'tight' membrane in a MBR to achieve higher quality permeate. For example, Choi et al. (2002) have used NF membranes in place of MF or UF. However, this approach has a problem with very low fluxes $\left(<1 \mathrm{~L} / \mathrm{m}^{2} \mathrm{~h}\right)$ when used in a submerged MBR. A more radical approach is to use MD as the separation stage (Phattaranawik et al. 2008). The membrane distillation bioreactor (MDBR) requires the reactor to operate at elevated temperature, such as $50^{\circ} \mathrm{C}$, to provide sufficient driving force so it uses thermophilic bacteria. MD only transmits volatile species so that all salts and most organics are retained giving a very high quality permeate. Fluxes up to $101 / \mathrm{m}^{2} \mathrm{~h}$ have been obtained and stable flux values of $5 \mathrm{~L} / \mathrm{m}^{2} \mathrm{~h}$ maintained over an extended period. Another promising option is the FOMBR which also provides a 'tight' membrane barrier (Achilli et al. 2009). Both the MDBR and FOMBR process must be operated on waste heat to achieve the low GHG emissions benefit. In the case of the FOMBR, the waste heat is required to regenerate the $\mathrm{DS}$ and recover product water (using RO to regenerate the draw would not be a low GHG option).

\section{MBRs}

The adoption of the MBR by the water industry over the past decade has been a paradigm shift. This has come about due to factors including acceptance of modest fluxes and a significant drop in energy costs for control fouling. Although the air required to scour the membranes has dropped, there may be further opportunities to do so, including finding the optimized bubble size for submerged hollow fibers (Fane et al. 2005) and improved bubble distribution for submerged flat sheets (Ndinisa et al. 2006). A more radical approach could be to replace or supplement the air scour my mechanical vibrations (Genkin et al. 2006).

Strategies are also emerging that alleviate membrane fouling in MBRs by controlling the condition or nature of the biomass. For example, additives have been developed (Yoon and Collins 2006) that appear to incorporate the supernatant foulants (EPS, colloids and planktonic bacteria) into the biofloc and thereby increase the 'sustainable' fluxes and allow savings in both membranes and energy usage. Another interesting approach is the moving biofilm MBR (BF-MBR) (Leiknes and Odegaard 2007), where the biomass is supported on floating carriers in an aerated chamber and membrane filtration is performed in a separate downstream chamber. The BF-MBR is able to sustain fluxes of about $50 \mathrm{~L} / \mathrm{m}^{2} \mathrm{~h}$ which is double that of conventional MBRs; conversely, the BF-MBR should be able to operate at conventional fluxes with slower TMP development and/or using less air scour.

\section{MBRs: energy issues}

In the context of MBRs, there are several approaches to 'lower carbon' solutions. The overall wastewater process provides conversion of the biodegradable organic carbon to $\mathrm{CO}_{2}$ and the conventional aerobic MBR requires net energy input for aeration and membrane fouling control. The incentive to reduce net GHG emissions makes anaerobic processing more attractive if the methane generated can be captured and used to offset the energy required to run the process. For example, we have investigated the treatment of a high strength wastewater (COD, 15,000 mg/L) using an anaerobic UASB followed by an aerobic SBR and then MF for effluent polishing (Parameshwaran et al. 2003). It was estimated that this process could yield a net energy of $2.5 \mathrm{kWh} / \mathrm{m}^{3}$ water treated. For municipal wastewaters, it is more challenging due to the lower carbon load, and potentially lower yield of methane per unit carbon (Cakir and Stenstrom 2005). A strategy to overcome this could involve membrane preconcentration of the wastewater. The other limitation of anaerobic processing is the lower BOD removal than for aerobic processing. An interesting option is to combine anaerobic processing (UASB or AnMBR) with polishing in an 'engineered' algal-bacterial MBR that treats the $\mathrm{CO}_{2}$ and residual carbon. Munoz and Guieysse (2006) have pointed out that the algal-bacterial process can improve the yield of methane biogas if the algae are harvested and returned to the anaerobic reactor. A novel AnMBR incorporating fluidized granular activated carbon has shown promising results (Kim et al. 2011). Clearly, there are many technical challenges in harnessing the potential energy offsets in anaerobic processing as well as opportunities for membrane technology. It will be important to quantify the benefits by life cycle assessment (LCA) of the GHG emissions.

Finally, the direct production of electrical power from biodegradable carbon has been demonstrated in the microbial fuel cell (MFC; Logan et al. 2006). This intriguing process uses bacteria to oxidize the organic carbon to generate an electrical current. The anode compartment is separated from the cathode by a proton conducting membrane, which justifies considering the MFC as 
a novel type of MBR. The MFC can also be modified to generate hydrogen in the cathode compartment, and is then considered to be a biochemically assisted microbial reactor (BEAMR). In addition to the microbiology, electrochemistry and membrane developments required, there are challenges in scale-up for control of concentration polarization and feed pretreatment. According to Logan et al. (2006), 'the growing pressure on our environment and the call for renewable energy sources will further stimulate development of this technology'. Improved membrane technology will be part of this development.

\section{Decentralization}

Much of the above discussion and potential developments could relate to decentralization of water supply and sanitation. Decentralized membrane systems, such as water filters and MBRs, provide benefits from a sustainability perspective (Fane and Fane 2005) as well as potentially tackling the MDGs for developing regions (DiGiano et al. 2004). However, to apply membranes successfully in decentralized systems, we need to make advances in several areas including (Fane and Fane 2005):

- lower system costs and affordability,

- minimization of energy demand,

- maximization of nutrient removal for beneficial use,

- integrity monitors that are low cost, reliable and remotely accessible,

- planning tools that account for the advantages of membrane based decentralization.

\section{Conclusions}

Membrane technology is now a major component of water production, wastewater treatment and reclamation. The technology has technical challenges that include improved performance in terms of permeate quality and fouling control and socio-economic challenges in response to climate change and the MDGs. In desalination, there are opportunities to improve both membranes and modules. The future may also include novel techniques such as MD, FO and advanced EDR. Water treatment could see better membranes with both higher permeability and tighter cutoff, and the more common use of ceramic membranes. For both desalination and water treatment, there are examples where lower energy, and GHG emissions, can be obtained but at a capital cost penalty; this points to a possible paradigm shift in process specification. Water reclamation by RO could be assisted by improved biofouling control strategies under development. An alternative low pressure process combining a bioreactor and MD or FO has the potential to provide reclaimed water with less GHG emissions. MBRs continue to evolve including the moving biofilm MBR which has biomass supported on floating media and thereby achieves higher sustainable fluxes. Wastewater processing also provides opportunities to reduce net GHG emissions by using anaerobic MBRs. In the longer term energy from wastewater could come from the MFC, another form of MBR. Finally, membranes are very well suited to decentralized processing of water and wastewater, which is required to satisfy the MDGs. Improvements in affordability and integrity monitoring are required.

Open Access This article is distributed under the terms of the Creative Commons Attribution License which permits any use, distribution and reproduction in any medium, provided the original author(s) and source are credited.

\section{References}

Achilli A, Cath TY, Marchand EA, Childress AE (2009) The forward osmosis membrane bioreactor: a low fouling alternative to MBR processes. Desalination 239(1-3):10-21

Anderson J (2007) Adapting to climate change with water savings and water reuse. In: Proceedings of IWA conference Reuse07, Sydney, July 2007

Barraud N et al (2009) NO-mediated dispersal in single- and multispecies biofilms. Microb Biotechnol 2:370-378

BCC Research (2007) Report. Advanced technologies for municipal water treatment (MST036B)

Birkett J, Truby R (2007) A figure of merit for appreciating improvements in $\mathrm{RO}$ membrane element performance. IDA Newsletter, March 2007

Cakir FY, Stenstrom MK (2005) Greenhouse gas production: a comparison between aerobic and anaerobic wastewater treatment technology. Water Res 39:4197-4230

Cath TY, Childress AE, Elimelech M (2006) Forward osmosis: principles, applications and recent developments. J Membr Sci 281(1-2):70-87

Chan MT, Fane AG, Matheickal JT, Sheikholeslami R (2005) Membrane distillation crystallization for processing of aqueous concentrate. J Membr Sci 257(1-2):144-155

Choi J-H, Doccko S, Fukushi K, Yamamoto K (2002) A novel application of a submerged nanofiltration membrane bioreactor for wastewater treatment. Desalination 146:413-420

Cote P, Siverns S, Monti S (2005) Comparison of membrane-based solutions for water reclamation and desalination. Desalination 182(1-3):251-257

DiGiano $F$ et al (2004) Membrane bioreactor technology and sustainable water. Water Environ Res 76(3):195-196

Fane AG, Fane S (2005) The role of membrane technology in sustainable decentralized wastewater systems. Water Sci Technol 51(6-7):317-325

Fane AG, Yeo A, Law A, Parameshwaran K, Wicaksana F, Chen V (2005) Low pressure membrane processes-doing more with less energy. Desalination 185(1-3):159-165

Genkin G, Waite TD, Fane AG, Chang S (2006) The effect of vibration and coagulation addition on the performance of submerged hollow fibre membranes. J Membr Sci 281(1-2):726-734 
Hochstrat R, Wintgens T, Melin T, Jeffrey P (2006) Assessing the European wastewater reclamation and reuse potential - a scenario analysis. Desalination 188:1-8

Holt JK et al (2006) Fast mass transport through sub-2 nanometer carbon nanotubes. Science 312:1034

Jeong B-H, Hoek EMV et al (2007) Interfacial polymerization of thin film nanocomposites: a new concept for reverse osmosis membranes. J Membr Sci 294:1-7

Kim J, Kim K, Ye H, Lee E, Shin C, McCarty PL, Bae J (2011) Anaerobic fluidized bed membrane bioreactor for wastewater treatment. Environ Sci Technol 45(2):576-581

Koros WJ (2006) Presentation at ECI membrane conference, Cetraro, Italy, June 2006

Kumar M et al (2007) Highly permeable polymeric membranes based on the incorporation of the functional water channel, Aquaporin Z. Proc Natl Acad Sci USA 104:20719-20724

Leiknes T, Odegaard H (2007) The development of a biofilm MBR. Desalination 202(1-3):135-143

Logan BE, Hamelers B, Rozendal R, Schroder U, Keller J, Fregia S, Aelterman P, Verstraete W (2006) Microbial fuel cells: methodology and technology. Environ Sci Technol 40(17):5181-5192

Macedonio F, Katzir L, Geisma N, Simone S, Drioli E, Gilron J (2011) Wind-Aided Intensified eVaporation (WAIV) and Membrane Crystallizer ( $\mathrm{MCr}$ ) integrated brackish water desalination process: advantages and drawbacks. Desalination, Online 5 Jan 2011

Morehouse JA et al (2006) The effect of uni-axial orientation on macroporous membrane structure. J Porous Mater 13:63-75

Munoz R, Guieysse B (2006) Algal-bacterial processes for the treatment of hazardous contaminants: a review. Water Res 40:2799-2815

Ndinisa NV, Fane AG, Wiley DE (2006) Fouling control in a submerged flat sheet membrane system. Part I. Bubbling and hydrodynamic effects. Sep Sci Technol 41(7):1383-1410
Pankratz T (2010) Global water intelligence. Water Desalination Report 2010-27

Parameshwaran K, Fane AG, Cho BD, Moosbruger R, Kim KJ (2003) Low energy treatment system for brewery wastewater reuse. In: Proceedings of the IWA world congress, Melbourne, April 2002, Water Sci Technol Water Supply, 3:141-148

Phattaranawik J, Fane AG, Pasquier ACS, Wu B (2008) A novel membrane bioreactor based on membrane distillation. Desalination 223(1-3):386-395

PWN website: http://www.pwntechnologies.nl

Sadr Ghayeni SB, Beatson PJ, Fane AG, Schneider RP (1999) Bacterial passage through MF membranes in wastewater applications. J Membr Sci 153(1):71-82

Schwinge J, Neal PR, Wiley DE, Fletcher DF, Fane AG (2004) Spiral wound modules and spacers: review and analysis. J Membr Sci 242(1-2),129-153. Skyjuice Foundation, http://www.skyjuice. com.au

Tangsubkul N, Parameshwaran K, Lundie S, Fane AG, Waite TD (2006) Environmental life cycle assessment of a microfiltration process. J Membr Sci 284(1-2):214-226

Truby RL (2008) Seawater desalination by ultra low energy RO. In: Li N, Fane AG, Ho WS, Matsuura T (eds) Advanced membrane technology and applications. Wiley, ISBN: 978-0-471-73167-2

United Nations (2006) MDG progress report. http://www.un.org/ milleniumgoals

Wang R, Shi L, Tang CY, Chou S, Qiu C, Fane AG (2010) Characterization of novel forward osmosis hollow fiber membranes. J Membr Sci 355:158-167

Yoon S-H, Collins JH (2006) A novel flux enhancing method for membrane bioreactor processes using polymer. Desalination 191(1-3):52-61 